\title{
Carbonized Steel-Smelting Slag Is a Promising Raw Material for the Production of Artificial Concrete
}

\author{
Igor Romanenko ${ }^{1, a *}$, Alexey Fadin ${ }^{1, b}$ and Maria Romanenko ${ }^{1, \mathrm{c}}$ \\ ${ }^{1}$ Penza State University of Architecture and Construction, 28 German Titov, Penza, 440028, \\ Russia \\ a rom1959@yandex.ru, b fadin@tulpm.ru, cromanenko.masha@yandex.ru
}

Keywords: Steelmaking Slag, Carbon Dioxide, Carbonization, Matrix, Structure, Hydration, Clinker Fund, Strength

\begin{abstract}
Obtaining an artificial stone based on steel-smelting slag is possible as a result of carbonization of the feedstock in carbon dioxide. The feedstock - slag and carbon dioxide - are byproducts from steel smelting in electric furnaces, which must be disposed of in order to improve the environmental situation in the region. The condition for obtaining the cementing ability of steelmaking slag is the preparation of a charge with certain properties and maturation technology: humidity, dispersion of the fine fraction and the maximum size of the coarse fraction, the ratio between the coarse and dispersed fractions, the concentration of carbon dioxide in the gas-air environment, temperature, pressure and flow time. carbonization reactions in the reactor, the magnitude of the pressure during the production of pressed articles, the process of stone maturation in the post-carbonization period.
\end{abstract}

\section{Introduction}

In the global balance of industrial waste emissions, and in particular, steel production slag is 240$300 \mathrm{ml}$. tons per year, which negatively affects the environment [1]. It is required to develop a number of measures and on their technologies for the inclusion of waste in the production cycle of obtaining materials for construction purposes with high performance characteristics. In general, blast furnace slags [2] are widely used in the production of a hydraulic binder, since they correspond to a stable material and mineralogical composition. Steel-making slags are practically not used due to the content of calcium and magnesium oxide $(>10 \%)$, their volumetric stability, which leads to cracking in an alkaline medium, and the $\mathrm{pH}$ of the medium is $>10[2,3]$.

We proposed a technological approach to obtain a durable artificial stone due to a molding composition on an optimized compositional matrix that underwent volumetric pressure and carbonization in a reactor, the starting material did not contain such substances as $\mathrm{Ca}(\mathrm{OH})_{2}$, $\mathrm{Mg}(\mathrm{OH})_{2}, \mathrm{SiO}_{2}$.

This approach is not new. Many researchers tried to obtain a stone as a result of the action of carbon dioxide on molded products from slag in a reactor [3, 4], but the carbonization processes affected the surface zone and did not extend to the entire depth of the sample. The core remained not carbonized, and as a result of holding both in the normal hardening chamber and in the reactor, cracks formed on the surface of the samples, leading to self-destruction due to the transition of the $\beta_{-c 2 s}$ phase to $\gamma_{-c 2 s}$, which does not possess binding properties at high $\mathrm{pH}$ values $\geq 12$, and free $\mathrm{CaO}$ and $\mathrm{MgO}$ increase in volume $[5,6]$.

Therefore, an important role is played by the creation of an optimal internal structure of the stone, ensuring the penetration of $\mathrm{CO}_{2}$ into the sample to its entire thickness, and the aqueous medium played the role of an active conductor. 


\section{Materials, research methodology}

The purpose of the research is to identify the technological features of the production of smallsized elements based on steel production slags, activated by carbon dioxide.

For the study, steelmaking slags of the Novolipetsk Metallurgical Plant were used, the chemical composition is presented in Table 1.

Table 1. Chemical composition of steelmaking slag

\begin{tabular}{|c|c|c|c|c|c|c|c|c|c|c|c|}
\hline $\mathrm{MgO}$ & $\mathrm{Al}_{2} \mathrm{O}_{3}$ & $\mathrm{SiO}_{2}$ & $\mathrm{~S}$ & $\mathrm{CaO}$ & $\mathrm{MnO}$ & $\mathrm{FeO}$ & $\mathrm{Fe}_{2} \mathrm{O}_{3}$ & $\mathrm{TiO}_{2}$ & $\mathrm{R}_{2} \mathrm{O}$ & $\mathrm{Zn}$ & $\mathrm{C}$ \\
\hline 7,58 & 3,48 & 13,79 & 0,3 & 49,88 & 1,98 & 9,75 & 10,2 & 0,25 & 0,17 & 0,011 & 1,15 \\
\hline
\end{tabular}

Slag particle size (SPS) 0-2,5 mm, moreover, $30 \%$ of this slag has a particle size of 30 to 230 microns. The reaction medium was a reactor with the possibility of supplying carbon dioxide, raising the temperature (up to $200{ }^{\circ} \mathrm{C}$ ) and regulating the pressure inside the reactor. Samples from the prepared mixture were molded on a press with double-sided hyper-pressing with a force of 385 $\mathrm{kgf} / \mathrm{cm}^{2}$.

To achieve the optimum density and carbonization of SPS, the molding mixture is moistened to a moisture content of 0,1 . The reactor is preheated to $105-110{ }^{\circ} \mathrm{C}$. After loading the samples into the reactor, evacuation takes place $-0.7 \mathrm{~atm}$., $5 \mathrm{~min}$, then the $\mathrm{CO}_{2}$ pressure rises to $12 \mathrm{~atm}$. at a speed of 3-4 atm. $/ \mathrm{min}$. The temperature of the carbonization in the reactor is $105-110{ }^{\circ} \mathrm{C}$. Formed specimen cylinders with a diameter and height of $60 \mathrm{~mm}$. placed on a pallet in the reactor chamber (Fig. 1)

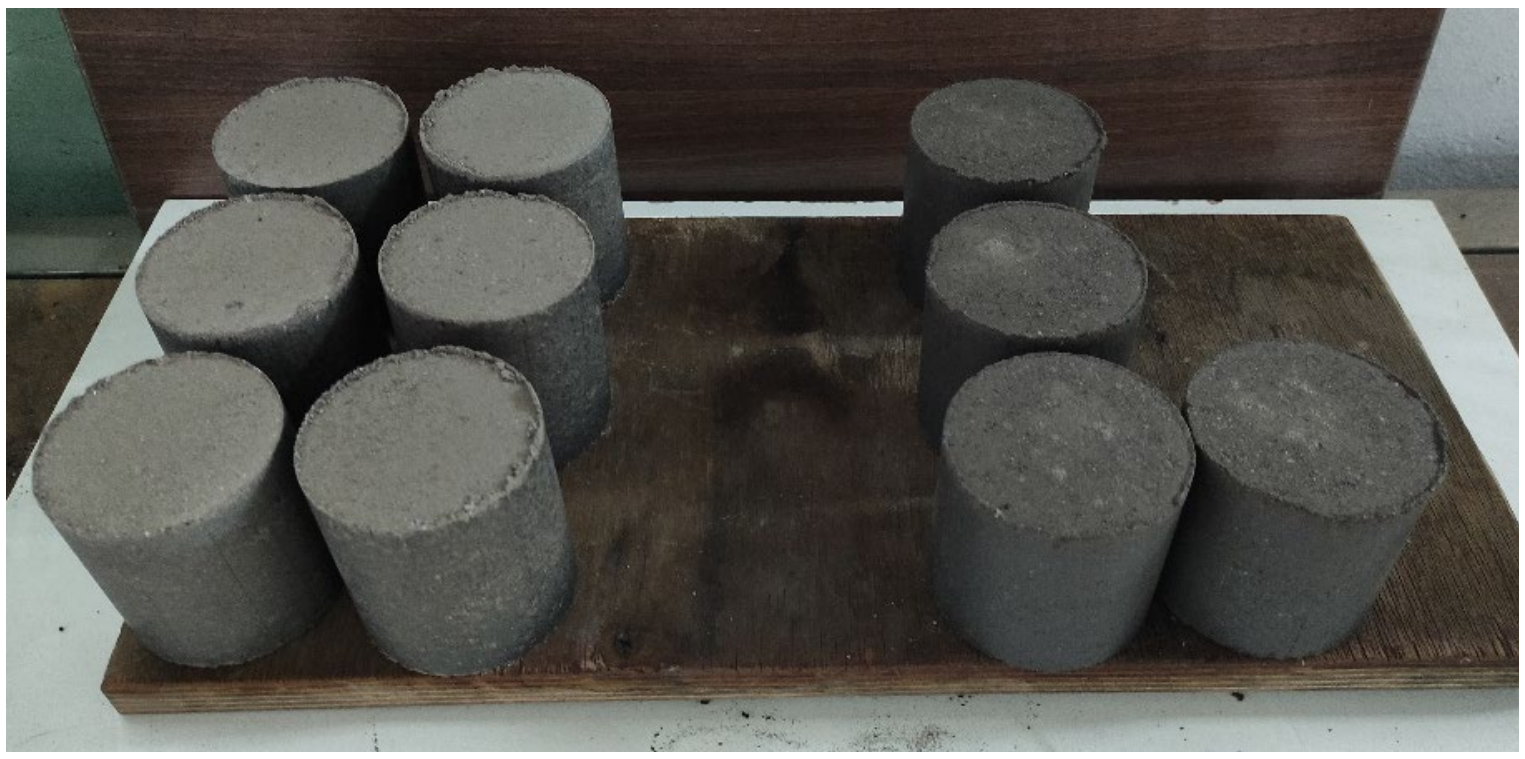

Fig. 1. Specimens molded from steelmaking slag of fraction $0-2,5 \mathrm{~mm}$, molding mixture - $100 \%$ wetted slag, mixture moisture $7,1 \%$

\section{Discussion}

After carbonization of the slag in the reactor for 14 hours, the samples had no cracks on their surface (Fig. 2). 
After inspecting the samples on the surface, there are 1 or 2 shots of the surface layer with a diameter of 2-5 mm and a depth of 1-2 $\mathrm{mm}$. The overall surface is smooth, uniformly gray, without cracks or flaking. Exposure in a normal hardening chamber at a temperature of $20{ }^{\circ} \mathrm{C}$ and a humidity of $90 \%$ for 28 days did not affect the quality and condition of the surface of the samples.

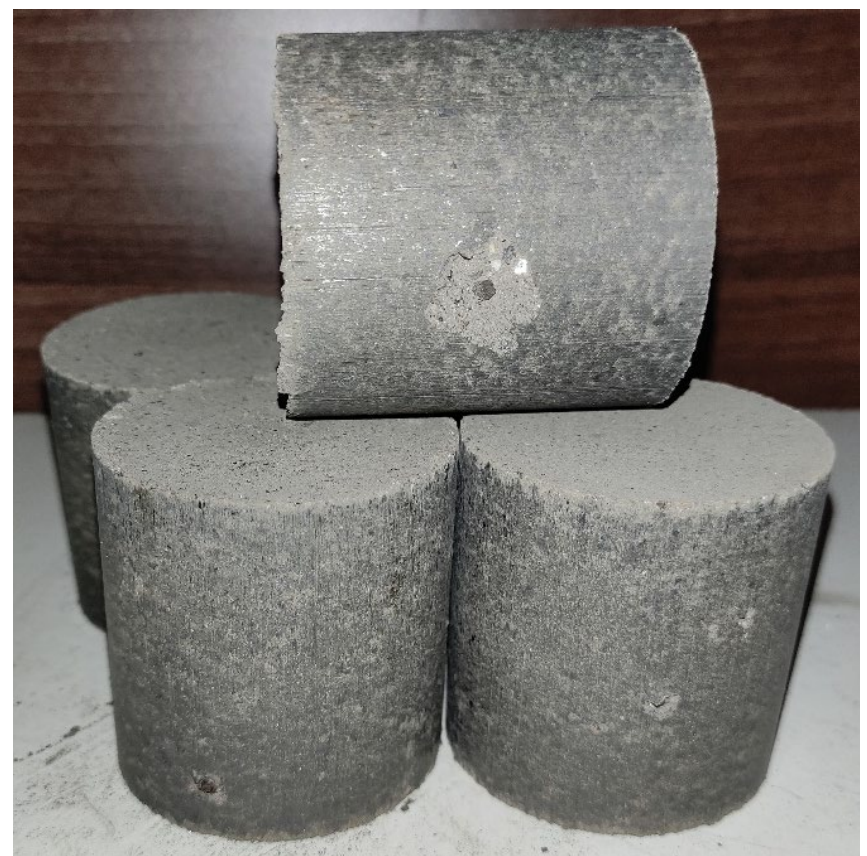

Fig. 2. Samples from steelmaking slag fraction after carbonization in the reactor after 14 hours

The compressive strength of the samples is $15,1-25,0 \mathrm{MPa}$, the density is $2340-2398 \mathrm{~kg} / \mathrm{m}^{3}$. The studies carried out on the split of the sample in order to determine the depth of carbonization showed by the intensity of the color of the indicator applied to the cut, that in the central part the intensity is weak and is approximately $25-30 \%$ relative to the intensity of the outer layer.

Investigations [7-9] carried out to determine the phase composition of steelmaking slag after carbonization reactions in the reactor and in the $\mathrm{CO}_{2}$ environment after 14 hours established the formation of the following minerals: $\mathrm{CaCO}_{3}$ calcite and calcium silicate hydrate $\mathrm{CSH}, \mathrm{MgCO}_{3}$ magnesite, $\mathrm{Ca}_{3} \mathrm{Mg}\left(\mathrm{SiO}_{4}\right)_{2}$ merwinite and $\mathrm{FeO}$ wustite.

\section{Conclusions}

The studies carried out have shown the possibility of obtaining low-grade concrete by carbonization of steel-making slag in a reactor in a carbon dioxide environment.

The use of steelmaking slag as a binder and filler according to traditional technology in the manufacture of building products is not acceptable due to the destruction of the structure of concrete from stresses caused by significant volumetric changes by $\mathrm{CaO}$ hydration products.

On the basis of steelmaking slag without adding Portland cement to the molding mixture due to carbonization, it is possible to produce wall stones of grades 100, 150 and 200 by optimizing the granular composition of the molding mixture, creating an optimal structure of artificial stone for the penetration of carbon dioxide through the molded samples.

The production of small-sized materials for road construction works based on slags from steelmaking production must strictly comply with the established technological regulations: the moisture content of the molding mixture, the temperature of the medium inside the reactor, the 
holding of a given pressure in the reactor, the concentration of $\mathrm{CO}_{2}$ in the air of the reactor, the time of preliminary holding of the samples before raising the pressure in the reactor.

\section{References}

[1] S.Y. Pan, $\mathrm{CO}_{2}$ mineralization and utilization by alkaline solid wastes for potential carbon reduction. Nature Sustainability, 3(5), (2020) 399- 405. https://doi.org/10.1038/s41893-0200486-9

[2] Y.N. Sheen, D.H. Le, and T.H. Sun, Innovative usages of stainless steel slags in developing self-compacting concrete. Construction and Building Materials, 101 (2015) 268-276.

https://doi.org/10.1016/j.conbuildmat.2015.10.079

[3] A.S. Brand and J.R. Roesler, Steel furnace slag aggregate expansion and hardened concrete properties. Cement \& Concrete Composites, 60 (2015) 1-9.

https://doi.org/10.1016/j.cemconcomp.2015.04.006

[4] P.S. Humbert and J. Castro-Gomes, $\mathrm{CO}_{2}$ activated steel slag-based materials: A review. Journal of Cleaner Production, 208 (2019) 448-457.

https://doi.org/10.1016/j.jclepro.2018.10.058

[5] I. Romanenko, A. Fadin, Optimization of Compositions and Hardening Conditions of Vibropress Concretes Based on Steel-Making Slag. Materials Science Forum, 1037 (2021) 715 720. https://doi.org/10.4028/www.scientific.net/MSF.1037.715

[6] I. Romanenko, A. Fadin, Steekmaking Slag - A Complex Material for the Production of Small-Size materials Using Hyper-Press Technology. Materials Science Forum, 1037 (2021) 737-742. https://doi.org/10.4028/www.scientific.net/MSF.1037.737

[7] A.A. Ruzavin, Disposal of Steelmaking Slags by Accelerated Carbonation. Bulletin of the South Ural State University. Ser. Construction Engineering and Architecture, 3(18) (2018) 6872. https://doi.org/10.14529/build180310

[8] I.I. Romanenko, M.I. Romanenko, I.N. Petrovnina, Modification of the cement stone active silm of urban treatment facilities. IOP Conference Series: Materials Science and Engineering. International Conference on Modern Trends in Manufacturing Technologies and Equipment 2019, ICMTME 2019 (2020) 022096. https://doi.org/10.1088/1757-899X/709/2/022096

[9] I.I. Romanenko, I.N. Petrovnina, M.I. Romanenko, Modification of the binder with finely ground components. Science diary, 2(14) (2018) 10. 